\title{
Prevalence and allele frequency of Congenital Colour Vision Deficiency (CCVD) among students at Hawassa University, Ethiopia
}

Reta Gutema Mitiku', Bekele Serbessa Tolera ${ }^{2}$ and Zelalem Gebremariam Tolesa ${ }^{3 *}$ (D)

\begin{abstract}
Background: The prevalence of congenital colour vision deficiency (CCVD) varies from race to race and differs in different geographic regions. Colour vision deficiency or colour blindness, is the inability or decreased ability of discriminating certain colour combinations and colour differences under normal lighting conditions. This study aimed to determine the prevalence of congenital colour vision deficiency among students at Hawassa University.

Methods: A cross-sectional survey was employed involving 4004 students (females $=1171$ and males $=2833$ ) from four campuses, namely, Institutes of Technology, College of Health Science and Medicine, College of Agriculture and Main Campus. The Ishihara pseudo-isochromatic 24 plate edition was used to test the colour vision of students under natural day light condition.

Results: The prevalence of CCVD in the present study was 2.85\%. A hundred and six (3.75\%) males and eight $(0.68 \%)$ females were affected with congenital colour vision deficiency. The frequencies of achromacy, deutan and protan in male subjects were $4(0.14 \%), 82(2.89 \%)$, and $24(0.85 \%)$, respectively. Deutan was highest among students of Amhara ethnic origin $(38,2.51 \%)$, but the frequency of protan was highest amongst Oromo students $(10,0.8 \%)$.

Conclusion and recommendations: The overall prevalence of CCVD found in the present study was lower compared to the previous studies done in Ethiopia. There was clear variation in the prevalence of colour vision deficiency among students of various ethnic groups. Proper screening, education and counseling are needed to minimize impacts of CCVD in the country, and can also be beneficial for the affected subject in tackling difficulties in everyday work and for proper choice of future profession.
\end{abstract}

Keywords: Colour vision deficiency, Deutan, Protan, Red-green deficiency, X-linked recessive

\section{Introduction}

Normal colour vision in humans is mediated by the three classes of cone photoreceptors (trichromatic colour vision): the blue or shortwave-sensitive (S), the green or middle-wave-sensitive (M), and red or longwave-sensitive (L) [1]. Colour vision deficiency (CVD), is the inability or decreased ability to discriminate certain colour combinations and colour differences under normal lighting conditions. Most colour vision defects are

\footnotetext{
* Correspondence: basliel2018@gmail.com

${ }^{3}$ Department of Biology, Hawassa University, Hawassa, Ethiopia

Full list of author information is available at the end of the article
}

congenital and permanent, but rarely it may be acquired $[2,3]$. Red-green defects (Protan and Deutan) show the highest prevalence in the general population. Red-green colour blindness, is genetically determined by X-linked recessive gene [4]. The genes causing red-green defects are localized to the long arm of the $\mathrm{X}$ chromosome at $\mathrm{Xq} 28$ [5-8], whereas the blue pigment gene is located on an autosome, chromosome 7 at $7 \mathrm{q} 32$ [7-10]. Green pigment genes vary in number among colour-normal individuals and, together with a single red pigment gene, are proposed to reside in a head-to-tail tandem array within the X chromosome [9]. Acquired CVD may be 
caused due to factors such as damage to the optic nerves, metabolic disorders (e.g., diabetes), eye diseases (e.g., glaucoma, macular degeneration), chronic illness (e.g., sickle cell anemia), drug overdose (e.g., barbiturates, digoxin, anti-tubercular drugs) [11].

The prevalence of colour congenital blindness varies from race to race and differs in different geographic areas. For example, the prevalence is $3.36 \%$ in Saudi Arabia [12], $5.28 \%$, in Manipur (India) [13], 3.28\% in Shekhan City/Kurdistan region (Iraq) [14], 4.10\% in Welkite town (central Ethiopia) [15] and 2.50\% in Bhopal (India) [16]. For the gene being X-linked, the frequency of CCVDs varies between males and females and it is usually more frequent in males. The prevalence of CCVD in males is $5.58 \%$ in Nepal [17], 8.47\% in Erbil City (Iraq) [18] and $4.2 \%$ in Bhopal (India) [16]. The prevalence of CCVDs varies among females from population to population, for example, $0.46 \%$ among the Basque population (Spain) [19], 0.75\% in Saudi Arabia [12], and 0.93\% in Qazvin (Iran) [20].

People with defective colour vision are at a disadvantage, especially for employment in professions like pilots, drivers, in defense services and in technical fields like engineering and the medical profession [17, 21]. In addition, in some fields of studies such as electrical engineering, agriculture, laboratory, forensic sciences, chemical engineering, soil engineering and architectural engineering normal colour vision is important $[2,13$, 22]. In Ethiopia, there are a limited number of studies done to assess the prevalence of congenital colour vision deficiency and its potential professional impacts [23-28]. The objective of the present study was to assess the prevalence and allele frequencies of red-green colour vision defects among students at Hawassa University, Ethiopia.

\section{Materials and methods \\ 2.1 Study area}

The study was conducted at Hawassa University focusing on undergraduate and postgraduate students from four campuses, namely; Institute of Technology, College of Health Science and Medicine, College of Agriculture and the Main campus.

\subsection{Research design and study subjects}

A descriptive cross-sectional survey was conducted to determine the prevalence of congenital colour vision deficiency. The inclusion criteria were Ethiopian students, above 18 years old, with the normal eye condition and who gave their consent. In this study, 4020 study subjects participated, but only 4004 individuals (i.e. females $=1171$ and males $=2833$ ) were included for subsequent analysis as the remaining 16 subjects had incomplete data. Furthermore, study subjects were from 35 ethnic groups.

\subsection{Congenital colour vision deficiency test}

The Ishihara pseudo-isochromatic plates were used to assess the colour vision of students under natural day light condition. The numbered plates of the Ishihara chart were used and the abnormalities were judged following Ishihara's recommendation [29]. The colour vision testing plates were held at $75 \mathrm{~cm}$ from the subject and tilted at right angles to the line of vision. The study subject was asked to read the numbers seen in the test plates 1 to 17 . An assessment of the reading of plates 1 to 15 determines the normality or defectiveness of colour vision. If 13 or more plates are read correctly, the colour vision is regarded as normal. If only 9 or fewer plates are read correctly, the colour vision was regarded as red-green deficient. Achromacy subjects read correctly plate one only. The plates 16 and 17 are used to differentiate deutan and protan types of colour vision efficiency.

\subsection{Statistical analysis}

Statistical analyses were conducted using SPSS version 20 [30]. The Chi-square $\left(x^{2}\right)$ test was done to determine whether there was a significant difference between sexes and between ethnic groups.

\subsection{Allele frequency analysis}

Assuming that the populations are non-consanguineous, the frequencies of the normal allele (p), deutan allele (q) and protan allele (s) for colour blind subjects were calculated based on the Hardy-Weinberg law using the gene counting method as was done by Shah et al. [13]. The expected allele frequencies of females were calculated based on the affected males' allele frequencies but the actual allele frequencies of females were calculated based on the affected females.

\section{Results}

\subsection{Phenotypic frequency of congenital colour vision} deficiency

A total of 4004 study subjects took part in this study out of which 1171 (29.25\%) were females and 2833 (70.75\%) were males. The age of the study subjects ranged from 18 to 47 years with a mean of $21.25 \pm 2.642$ years. Of the total study subjects, 114 (2.85\%; $95 \%$ CI: 2.33 to 3.37 ) had congenital colour vision deficiency, including 106 males and 8 females (Table 1). The prevalence

of colour blindness in male and female students was $3.75 \%$ (95\% CI: 3.05 to 4.45 ) and $0.68 \%$, respectively.

In the present study, the subjects were from 35 different ethnic groups (Table 1). As the sample size of the majority of ethnic groups was small (except that of 
Table 1 The prevalence of congenital colour vision deficiency (CCVD) by gender and ethnic groups, Hawassa University, Ethiopia

\begin{tabular}{|c|c|c|c|c|c|c|c|c|c|}
\hline \multirow[b]{2}{*}{ Ethnic groups } & \multicolumn{3}{|l|}{ Combined } & \multicolumn{3}{|l|}{ Male } & \multicolumn{3}{|l|}{ Female } \\
\hline & Normal (\%) & Color blind (\%) & Total & Normal (\%) & Color blind (\%) & Total & Normal (\%) & Color blind (\%) & Total \\
\hline Amhara & 1465(96.96) & $46(3.04)$ & 1511 & 1024(95.88) & $44(4.12)$ & 1068 & $441(99.55)$ & $2(0.45)$ & 443 \\
\hline Oromo & 1109(96.94) & 35 (3.06) & 1144 & 732(96.06) & $30(3.94)$ & 762 & 377(98.69) & $5(1.31)$ & 382 \\
\hline Otherst & 1312(97.55) & $33(2.45)$ & 1345 & 967(96.80) & $32(3.20)$ & 999 & 345(99.71) & $1(0.29)$ & 346 \\
\hline Total & $3886(97.15)$ & $114(2.85)$ & 4000 & 2723(96.25) & $106(3.75)$ & 2829 & 1163(99.32) & $8(0.68)$ & 1171 \\
\hline
\end{tabular}

${ }^{\dagger}$ Afar (7), Agew (4), Alle (1), Antro (3), Anyuak (4), Arri (3), Awi (3), Bench (7), Burji (1), Dawuro (21), Dorze (2), Gamo (105), Gedeo (5), Gumuz (3), Gurage (182), Hadya (93), Halaba (13), Hamar (1), Harari (1), Kafa (14), Kambata (104), Konso (4), Kore (2), Kucha (3), Nyangatom (2), Shakacho (3), Shinasha (3), Sidama (306),Silte (39), Somali (20), Tegaru (193), Wolaita (191), and Yem (3) ethnic groups. The numbers in the brackets are the percentage of sample size subjects from the respective ethnic groups

Amhara and Oromo), we had combined them together to have a balanced sample size. Colour blindness was only recorded among subjects from 10 ethnic origins, namely; Amhara, Gurage, Halaba, Kafa, Kambata, Oromo, Sidama, Somali, Tegaru and Wolaita. Deutan was highest amongst students of Amhara ethnic origin 38 (2.51\%), but the frequency of protan was highest amongst Oromo students $10(0.87 \%)$. Nonetheless, the prevalences of deutan and protan were low in the other ethnic groups combined. The frequencies of anchromacy, deutan and protan were 4/0, 82/6 and 24/2, in males/females respectively (Table 2). The frequency of deutan and protan among females of the affected students was higher in Oromo ethnic origin. In this study, total colour blindness was not observed in females (Table 2).

\subsection{Allelic and genotypic frequency of CCVD among ethnic groups}

Since males are hemizygous (i.e. having a single $\mathrm{X}$ chromosome), the frequency of the CCVD allele in them would be the same as the proportion of colour blindness (e.g. Amhara $(44 / 1068=0.04)$, Oromo $(30 / 762=0.04)$ and the other ethnic groups $(32 / 999=0.03)$. Similarly, the observed (actual) frequencies in females were 0.005, 0.013 and 0.003 in Amhara, Oromo and other ethnic groups, respectively. Based on the frequencies of CCVD allele in males of the respective ethnic groups, the expected frequencies in females were $\left(0.04^{2}=0.0016\right)$ in Amhara and Oromo and $\left(0.03^{2}=0.0009\right)$ in the other ethnic groups combined. In this regard, the expected frequency of CCVD among female students of Oromo ethnic origin was 0.0016 and lower compared to the observed frequency $(0.013)$. The frequency of heterozygote was higher $(8.00 \%)$ in Amhara and Oromo but lower among study subjects in other ethnic groups combined (Table 3).

\section{Discussion}

The overall prevalence of CCVD in the present study was lower compared to the previous studies such as in Addis Ababa (Ethiopia), 4.52\%, by Abebe and Wondimkun [24], in Saudi Arabia, 3.36\%, by Oriowo and Alotaibi [12], in Manipur (India), $5.28 \%$, by Shah et al [13], in Shekhan City/Kurdistan region (Iraq), 3.28\%, by Abdulrahman [14], in Welkite town (central Ethiopia), 4.10\%, by Woldeamanuel and Geta [15] but higher than a report in Bhopal (India), $2.50 \%$ by Gupta et al. [16]. The lower prevalence of CCVD in the present study relative to other studies conducted in Ethiopia [24, 25], could be due to the larger sample size of the current study. In this study, the majority of students were unaware about colour vision deficiency disease, except students from Health Science and Medicine.

The prevalence of CCVD recorded in males in the present study (3.75\%) was similar to the reports in western Nepal (Pokhara, 3.80\%) [31] and in Rajasthan (India, $3.20 \%$ [32]. Yet the frequency of CCVD recorded amongst males in this study was low relative to investigations in Tehran (8.20\%) [33], in Denmark (8.67\%) [34], in Nepal (5.58\%) [17], in Erbil City (Iraq, 8.47\%) [18] and in Bhopal (India, $4.20 \%$ ) [16]. However, the prevalence of the CCVD (males) in the present study was higher than that of India (2.30\%) [35] and in Qazvin (Iran, 2.56\%) [20].

Table 2 Phenotypic frequency of achromacy and the different types of CCVD among male and female students of various ethnic groups in Hawassa University, Ethiopia

\begin{tabular}{|c|c|c|c|c|c|c|c|c|}
\hline \multirow{2}{*}{$\begin{array}{l}\text { Ethnic } \\
\text { groups }\end{array}$} & \multicolumn{4}{|l|}{ Male } & \multicolumn{4}{|l|}{ Female } \\
\hline & Achromacy (\%) & Deutan (\%) & Protan (\%) & Total & Achromacy (\%) & Deutan (\%) & Protan (\%) & Total \\
\hline Amhara & $2(0.19)$ & $36(3.36)$ & $8(0.75)$ & 1070 & $0(0.00)$ & $2(0.45)$ & $0(0.00)$ & 443 \\
\hline Oromo & $1(0.13)$ & $22(2.88)$ & $8(1.05)$ & 763 & $0(0.00)$ & $3(0.79)$ & $2(0.52)$ & 382 \\
\hline Others & $1(0.10)$ & $24(2.40)$ & $8(0.80)$ & 1000 & $0(0.00)$ & $1(0.29)$ & $0(0.00)$ & 346 \\
\hline Total & $4(0.14)$ & $82(2.89)$ & $24(0.85)$ & 2833 & $0(0.00)$ & $6(0.51)$ & $2(0.17)$ & 1171 \\
\hline
\end{tabular}


Table 3 The frequencies of normal, heterozygote, double heterozygote and colour blind male and female subjects

\begin{tabular}{|c|c|c|c|c|c|c|c|c|c|}
\hline \multirow{3}{*}{$\begin{array}{l}\text { Ethnic } \\
\text { group }\end{array}$} & \multicolumn{9}{|l|}{ Gender } \\
\hline & \multicolumn{4}{|l|}{ Male } & \multicolumn{5}{|l|}{ Female } \\
\hline & Normal & Deutan & Protan & Total & Deutan & Protan & Heterozygote & Double heterozygote & Colour blind \\
\hline \multirow[t]{2}{*}{ Amhara } & 1024 & 36 & 8 & 1068 & $q^{2}=0.001$ & $s^{2}=0.0001$ & $2(p q+p s)=0.08$ & $2 q s=0.001$ & $q^{2}+s^{2}=0.0011$ \\
\hline & $p=0.96$ & $q=0.03$ & $s=0.01$ & & & & & & \\
\hline \multirow[t]{2}{*}{ Oromo } & 732 & 22 & 8 & 762 & & & & & \\
\hline & $p=0.96$ & $q=0.03$ & $s=0.01$ & & $q^{2}=0.001$ & $s^{2}=0.0001$ & $2(p q+p s)=0.08$ & $2 q s=0.001$ & $q^{2}+s^{2}=0.0011$ \\
\hline \multirow[t]{2}{*}{ Other } & 967 & 24 & 8 & 999 & & & & & \\
\hline & $p=0.97$ & $q=0.02$ & $s=0.01$ & & $q^{2}=0.0004$ & $s^{2}=0.0001$ & $2(p q+p s)=0.06$ & $2 q s=0.0004$ & $q^{2}+s^{2}=0.001$ \\
\hline \multirow[t]{2}{*}{ Total } & 2723 & 82 & 24 & 2829 & & & & & \\
\hline & $p=0.96$ & $q=0.03$ & $s=0.01$ & & $q^{2}=0.001$ & $s^{2}=0.0001$ & $2(p q+p s)=0.08$ & $2 q s=0.001$ & $q^{2}+s^{2}=0.0011$ \\
\hline
\end{tabular}

Several studies indicated that the prevalence of CCVD in females is usually lower as compared to that of males (e.g., [12, 13, 23, 31]). The prevalence of CCVD amongst females in the present study was higher than in Italy $(0.10 \%)$ [36], in northern Ethiopia (0.20\%) [23], but comparable to that of Saudi Arabia (0.75\%) [12] and in Qazvin(Iran, 0.93\%) [20]. A relatively higher frequency of CCVD in females is reported by couples of studies, for examples, in the Punjab city of India, (1.10\%) [37] and Erbil City (Iraq, 1.37 \%) [18]. However, studies conducted in Libya [35], in western Nepal (Pokhara) [31], in Rajasthan (India) [32] reported no cases of CCVD amongst female subjects. On the contrary, studies done in Faisalabad (Pakistan) [38] and in Kolkata (West Bengal/India) [39] reported a higher prevalence of CCVD in females compared to males. The higher prevalence amongst males as compared to females indicates the genetic causation of the disorder [4-10]. Congenital colour vision deficiency is genetically determined by $\mathrm{X}$ linked recessive inheritance and thus occurs in males but is transmitted via females and about $8.0 \%$ of all women are carriers [40].

The prevalence of achromacy in this study was comparable with Abeshge district (central Ethiopia, 0.19\%) [25] and in Ugep (Nigeria, 0.20\%) [41]. On the other hand, the prevalence of deutan in males (2.89\%) was lower compared to the northwest Ethiopia (3.20 \%) [23], but similar to Abeshge district (2.89\%) [25].

The prevalence of CCVD amongst students of Amhara (3.04\%) and Oromo (3.06\%) ethnic was lower compared to some ethnic groups in Nepal (e.g. 5.00\% in Brahman, $5.10 \%$ in Gurung, $9.10 \%$ in Newar and $14.30 \%$ in Darji) but higher relative to other ethnic groups (e.g. $2.8 \%$ in Chhetri and $2.1 \%$ in Magar) [31]. Furthermore, the prevalence of CCVD in males (3.75\%) and females $(0.68 \%)$ in the present study was lower compared to various ethnic groups in Iraq (e.g. 8.45\%/1.20\% (males/ females) in Kurd, 9.44\%/2.24\% in Arabs, $8.52 \% / 1.56 \%$ in Turkman, and $7.40 \% / 1.05 \%$ in Kldan) [18]. The lower frequencies of various types of CCVD in the present study compared to Iraq [18] and India [13], could be due to the common practices of consanguineous marriage in countries in the middle east and southeast Asia $[12,13,18,31,35]$. In this regards, in Ethiopia consanguineous marriage is rare as it is not promoted because of cultural, religious and legal factors. However, a couple other factors contribute for the difference in the prevalence of CCVD between populations and geographic regions, in addition to the degree of consanguineous marriage (e.g. population movements, the molecular structure of gene on the $\mathrm{X}$ chromosome, natural selection). For example, increasing migration of people within a country and across countries (e.g. in Saudi Arabia [12], in India [13]), might indirectly lead to increase in the rate of exogamous marriages that could contribute increase in the prevalence of CCVD. It is also suggested that increase incidence of colour blindness amongst the Caucasians may be due to difference in the molecular pattern of $\mathrm{X}$ chromosome of colour vision genes. Furthermore, it was observed that overall frequency of colour vision defects has been observed quite low amongst scheduled tribe groups (traditionally food gatherers and hunters and later occupied in shifting cultivation and as agricultural laborers) from all the zones in India followed by scheduled caste groups (about $90 \%$ of scheduled castes are agricultural laborers) which is followed by caste groups [13].

Average heterozygosity is a measure of genetic diversity at the population scale and indicates the average proportion of individuals that are heterozygous for a given trait. The frequencies of CCVD alleles found in the present study was lower compared to those of the frequencies reported in five populations in Manipur (India) [13] and for science students in the ASC Rahuri College (India) [42]. Furthermore, the level of heterozygosity found in the 
present study amongst female students of Amhara (8\%) and Oromo (8\%) ethnic origin was low compared to that of the population in India (e.g. Meitie (26.61\%), Sheikh (24.45\%) [13]. In addition, the heterozygosity documented in the present study for female students was almost half of that of the prevalence in a general population (14.70\%) [43]. Similarly, the frequency of double heterozygosity found in the present study for female subjects was one fifth of the prevalence in the general population [43]. Females who had a recessive allele for deutan on one $\mathrm{X}$ chromosome, but a recessive allele for protan on the second X chromosome are called 'double carriers' (or compound heterozygote) [43]. Carroll [43] has also examined a female subject who had one deutan son and a protan son, which indicated her identity of double heterozygote/ double carrier. Furthermore, the identity of this subject as both deutan and protan was also confirmed by genetic analysis. In the present analysis, we did not explicitly find double carrier subjects, but we do not rule out the possibility of getting such subjects.

In some jobs such as doctors, educational trainers and drivers, colour recognition is essential and hence detection of colour vision deficiency at an early age is useful to avoid certain occupational hazards [2, 13, 21, 22]. However, in Ethiopia, early testing of colour vision deficiency is not common when students join university to study fields like engineering, soil sciences, chemistry, electricity and electronics, etc. Since colour vision deficiency is not a deadly disease, an individual can be a colour vision deficiency without noticing the scene. Unnoticed deficiency may lead to professional inefficiency and some risks. A study conducted by Abebe and Wondmikun [24] on defective colour perception amongst licensed car drivers in Addis Ababa revealed a prevalence of $4.50 \%$ of colour vision impairment. Furthermore, the results showed that $31.8 \%$ of colour blind subjects had road traffic accidents the past three years prior to the study. They have also found that an examination of colour vision in driving license seekers in Ethiopia does not screen out colour-blind individuals. The likelihood that colour-blind drivers would encounter an accident is about twice as high as amongst non-colourblind drivers [24]. Therefore, in today's automated world, when every livelihood is connected with modern technology, analysis of colour vision deficiency is indispensable to mitigate the potential impact of colour vision deficiency $[2,13,21,24]$.

\subsection{Limitations}

The overall prevalence of CCVD found in the present study was lower compared to the previous studies done in Ethiopia. The prevalence of CCVD was highest amongst males, but relatively low amongst female subjects. There was a clear difference in the prevalence of colour vision deficiency amongst students of various ethnic groups. Many students were unaware of colour vision deficiency itself, except students from health science and medicine. Therefore, proper screening, education and counseling are needed to minimize the influences of colour vision deficiency in the country and could be beneficial to the affected subject in tackling difficulties in everyday work and for proper choice of future profession.

\section{Conclusion and recommendations}

Anomaloscope should be used for detailed analysis of quantitative and qualitative anomalies in colour perception. However, in this study, we did not use anomaloscope which is clinically used for screening and diagnosis of CVD, because the instrument was not available in our set up. Furthermore, we were not able to cover all the ethnic groups as it was not possible for logistic factors.

\section{Acknowledgements \\ The authors would like to thank all the participants for their cooperation and Hawassa University for giving ethical permission to conduct the research.}

\section{Authors' contributions}

RGM was involved in data collection and analyses. BST was involved in the study design, data analyses and manuscript revision and ZGT was involved in the study design, data analyses, manuscript writing and revision. All authors read and approved the manuscript.

\section{Funding}

Research fund was provided by the School of Graduate Studies (SGS) of Hawassa University.

\section{Availability of data and materials}

The data used in this study are available from the corresponding author on reasonable request.

\section{Ethics approval and consent to participate}

The study was conducted after ethical approval (Ref. No. IRB/134/10; Date 12/02/2018) of the Institutional Review Board (IRB) of Hawassa University (Ethiopia), College of Health Science and after an informed consent was obtained from each study subject.

\section{Consent for publication}

Consent for publication is not applicable as this study did not include names, images, or videos relating to individual participants.

\section{Competing interests}

We declare that there are no conflicts of interest amongst the co-authors. All the co-authors have contributed from the very inception of the manuscript and until the final version of the manuscript.

\section{Author details}

${ }^{1}$ Department of Biology, Dambi Dollo University, Dambi Dollo, Ethiopia. ${ }^{2}$ Department of Biology, Wollega University, Nekemte, Ethiopia. ${ }^{3}$ Department of Biology, Hawassa University, Hawassa, Ethiopia.

Received: 22 March 2019 Accepted: 7 February 2020

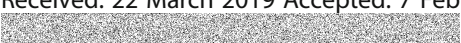

\section{References}

1. Agarwal S, Bansod N. Prevalence of colour blindness in school children. Int J of Sci Res. 2014;3(4):175-7.

2. Cumberland P, Rahi JS, Peckham CS. Impact of congenital colour vision defects on occupation. Arch Dis Child. 2005;90:906-8. 
3. Cole BL. The handicap of abnormal colour vision. Clin ExpOptom. 2004; 87(4-5):258-75.

4. Filosa S, Calabro V, Lania G, Vulliamy TJ, Brancati C, Tagarelli A, et al. G6PD Haplotypes Spanning Xq28 from F8C to Red/Green Colour Vision. Genomics. 1993;17:6-14.

5. Jagla WM, Jagle H, Hayashi T, Sharpe LT, Deeb SS. The molecular basis of dichromatic color vision in males with multiple red and green visual pigment genes. Hum Mol Genet. 2002;11(1):23-32.

6. Ueyama H, Muraki-Oda S, Yamade S, Tanabe S, Yamashita T, Shichida Y. Ogita H Unique haplotype in exon 3 of cone opsin mRNA affects splicing of its precursor, leading to congenital color vision defect. Biochem Biophys Res Commun. 2012;424(1):152-7.

7. Deeb SS, Kohl S. Genetics of colour vision deficiencies. Dev Ophthalmol. 2003:37:170-87.

8. Deeb SS. Molecular genetics of colour vision deficiencies. Clin. Exp. Optom. 2004;87:224-9.

9. Nathans J, Piantanida TP, Eddy RL, Shows TB, Hogness DS. Molecular genetics of inherited variation in human colour vision. Science. 1986; 232(4747):203-10

10. Motulsky AG. Normal and abnormal colour-vision genes. Am J Hum Genet. 1988:42:405-7.

11. Barrett KE, Barman SM, Boitano S, Brooks HL. Ganong's Review of Medical Physiology. 23 ${ }^{\text {rd }}$ ed. McGraw-Hill Companies; 2010; 714pp.

12. Oriowo OM, Alotaibi AZ. Colour vision screening among Saudi Arabian children. S Afr Optomol. 2008;67:56-61.

13. Shah A, Hussain R, Fareed M, Afzal M. Prevalence of Red-Green Colour Vision Defects among Muslim Males and Females of Manipur. India. Iran J Public Health. 2013;42(1):16-24.

14. Abdulrahman MA. Prevalence of Colour Vision Deficiency among Students in Hajand and Amad High Schools in Shekhan City Kurdistan. J App Res. 2017;2(2):1-5

15. Woldeamanuel GG. Geta TG Prevalence of colour vision deficiency among school children in Wolkite, Southern Ethiopia. BMC Res Notes. 2018;11:838

16. Gupta SC, Saxenna SP, Gupta S, Saxenna R, Sharma S. The prevalence of colour blindness in middle school student in southern Bhopal. Int J Med Health Res. 2017:3(5):111-3.

17. Pramanik T, Khatiwada B, Pandit R. Colour vision deficiency among a group of students of health sciences. Nepal Med Coll J. 2012;14(4):334-6.

18. Karim KJ, Saleem MA. Prevalence of congenital red-green color vision defects among various ethnic groups of students in Erbil City. Jordan J Biol Sci. 2013;6(3):235-8.

19. Rebato $E$, Calderon R. Incidence of red-green colour blindness in the Basque population. AnthropolAnz. 1990;48(2):145-8.

20. Khalaj M, Barikani A, Mohammadi M. Prevalence of colour vision deficiency in Qazvin. Zahedan J Res Med Sci (ZJRMS). 2014;16(1):91-3.

21. Moudgil T, Arora R, Kaur K. Prevalance of colour blindness in children. Int J Med and Dent Sci. 2016;5(2):1252-8.

22. Bansal Y, Singh D, Sreenivas M, Setia P, Garg V. Colour blindness: forensic perspective. JIAFM. 2005;27(1):43-5.

23. Zein ZA. Gene frequency and type of Colour blindness in Ethiopians. Ethiop Med J. 1990;28(2):73-5.

24. Abebe Y, Wondmikun Y. Defective colour perception among car drivers in Addis Ababa, Ethiopia. Traffic Injury Prevention. 2010;3(4):294-7.

25. MulusewA,Yilikal A. Prevalence of congenital colour vision defects among school children in five schools of Abeshge District, Central Ethiopia. J Ophthalmol Eastern, Central Southern Africa2013; 17(1):10-14.

26. Darge HF, Shibru G, Mulugeta A, Dagnachew YM. The prevalence of visual acuity impairment among school children at Arada Subcity primary schools in Addis Ababa, Ethiopia. J Ophthalmol. 2017:2017:1-7.

27. Wale MZ, Abebe Y, Adamu Y, Zelalem A. Prevalence of color blindness among school children in three primary schools of Gish-Abay town district, Amhara regional state, north-west Ethiopia. BMC Ophthalmology. 2018:18:306.

28. Bezabih L, Abebe TW, Fite OR. Prevalence and factors associated with childhood visual impairment in Ethiopia. Clin Ophthalmol. 2017:11:1941-8.

29. Ishihara S. The series of plates designed as a test for color deficiency. 24 plates, edition. Tokyo, Japan, KANEHRA SHUPPAN CO., LTD, 1972.

30. SPSS version 20@ Copyright IBM Corporation, 2011.

31. Niroula DR, Saha CG. The Incidence of colour blindness among some school children of Pokhara, Western Nepal. Nepal Med Coll J. 2010;12(1):48-50.
32. Kumar R, Kumar J, Soni ND, Choudhary R. Prevalence of colour blindness among school going children aged 10-17 years in Jodhpur city in Rajasthan Sch J Arts Humanit. Soc Sci. 2016;4(2A):126-9.

33. Modarres M, Mirsamadi M, Peyman GA. Prevalence of congenital color deficiencies in secondary-school students in Tehran. Int Ophthalmol. 1996; 20(4):221-2.

34. Norn M. Prevalence of congenital colour blindness among Inuit in East Greenland. Acta Ophthalmol Scand. 1997;75(2):206-9.

35. Rahman SA, Singh PN. MandaPK. Comparison of the Incidence of Colour blindness between sections of Libyans and Indians Populations. Indian J Physiol Pharmacol. 1998:42(2):271-5.

36. Floris G, Murgia E, Sanciu MG. Frequency of color blindness in Sardinia (Italy). Bulletins etMémoires de la Sociétéd'anthropologie de Paris. 1992; 4(1-2):105-10.

37. Bansal IJ. The frequency of colour blindness among the Punjabis of India. J Genet Human. 1967;16(1-2):1-5.

38. Mughal IA, Ali L, Aziz N, Mehmood K, Afzal N. Colour Vision Deficiency (Cvd) in medical students. Pak J Physiol. 2013;9(1):14-6.

39. Saha D, Saha K. Prevalence of Colour Vision Deficiency (CVD) in medical students in Kolkata, West Bengal. IOSR Journal of Dental and Medical Sciences (IOSR-JDMS).

40. Guyton AC, Hall JE. Textbook of Medical Physiology. 11th ed. Philadelphia, USA: Elsevier Publication; 2006. 1016 pp.

41. Ubom R. Prevalence of Congenital Colour Vision Deficiency in Nigerians living in Ugep, Cross Rivers State. MSc Thesis: University of Nigeria; 2011. $50 \mathrm{pp}$.

42. Panat AV, Kulkarni DA. Prevalence of red-green color vision deficiency (cvd) among science students: a 10 years' survey. Human Biology Review. 2016; 5(1):65-71.

43. Carroll J. Colour-blindness detective story not so simple. Clin ExpOptom. 2006:89(3):184-5.

\section{Publisher's Note}

Springer Nature remains neutral with regard to jurisdictional claims in published maps and institutional affiliations.

\section{Submit your manuscript to a SpringerOpen ${ }^{\circ}$ journal and benefit from:}

- Convenient online submission

- Rigorous peer review

- Open access: articles freely available online

- High visibility within the field

- Retaining the copyright to your article

Submit your next manuscript at $\boldsymbol{\nabla}$ springeropen.com 